\title{
INVESTIGAÇÃO DA PRESENÇA DE ELEMENTOS DA AVALIAÇÃO DE DESEMPENHO NA GERAÇÃO DE APRENDIZAGEM ORGANIZACIONAL: UM ESTUDO DE CASO
}

\section{INVESTIGATION OF THE PRESENCE OF ELEMENTS OF PERFORMANCE MANAGEMENT IN THE GENERATION OF ORGANIZATIONAL LEARNING: A CASE STUDY}

\author{
SANDRA MARA IESBIK VALMORBIDA \\ Universidade Tecnológica Federal do Paraná. Endereço: Via do \\ Conhecimento, Km 1| Fraron | 85503-390| Pato Branco /PR | Brasil. \\ (1) http://orcid.org/0000-0001-6607-7957 \\ smiesbik@gmail.com
}

\section{SANDRA ROLIM ENSSLIN}

Universidade Federal de Santa Catarina. Endereço: Campus Universitário Reitor João David Ferreira Lima, $s / n^{o}$ | Trindade | 88040-900| Florianópolis/SC| Brasil.

Dhttp://orcid.org/0000-0001-7420-8507

sensslin@gmail.com

\section{RESUMO}

Esta pesquisa investigou a presença dos elementos da Avaliação de Desempenho (AD) na geração de Aprendizagem Organizacional, pela percepção dos envolvidos no processo. Trata-se de um estudo de caso, com entrevistas de três pessoas diretamente envolvidas com o desenho, implementação, uso e retroalimentação do sistema. As entrevistas semiestruturadas foram orientadas pela literatura de base que aponta a presença dos elementos. Analisando as falas dos entrevistados, verifica-se que o sistema de AD foi construído num ciclo contínuo de reflexão, visto que as experiências de planejamento estratégico anteriores não prosperaram. Pela percepção dos entrevistados o sistema possibilitou à organização se dar conta da realidade, detectar e corrigir problemas existentes e, antes, não conhecidos. Assim, pode-se pensar em ações de melhorias. Ademais, ficou evidente que a comunicação permeou todo o processo de $\mathrm{AD}$, pois explicitou o que se desejava com a construção de métricas e direcionou o estabelecimento de metas. Estas, fomentaram a utilização das informações para gestão e garantiram feedback oportuno, permitindo a comparação dos resultados obtidos com aqueles esperados, definidos pelas metas colocadas. Esse feedback proporcionou a participação de todos os envolvidos, fazendo com que a organização pudesse verificar o alcance dos seus objetivos estratégicos, periodicamente retroalimentar o sistema, revisando sua estratégia, e rever suas crenças, comportamentos e ações, tornando a organização mais preparada para as mudanças ambientais. Por fim, pode-se concluir que a aprendizagem é percebida pelos gestores quando conseguem evidenciar o que a organização desejava atingir, refletir sobre a adequação dos objetivos perseguidos e demonstrar que a colaboração se dá em aperfeiçoar rotinas já desenvolvidas na organização. Também quando conseguem identificar o que é importante mensurar, parametrizar as metas, com esses dados, e instrumentalizar o feedback, de forma que possibilite analisar os resultados, comparando-os com as metas estabelecidas. E sobretudo, quando é possível confiar nas informações para balizar decisões.

Palavras-Chave: Avaliação de desempenho. Aprendizagem organizacional. Elementos geradores de aprendizagem. 


\begin{abstract}
This research investigated the presence of the elements of Performance Management (PM) in the generation of Organizational Learning, through the perception of stakeholders in the process. It is a case study, with interviews of three people directly involved with the design, implementation, use and feedback of the system. The semi-structured interviews were guided by the basic literature that points out the presence of the elements. Analyzing the speeches of the interviewees, it appears that the PM system was built in a continuous cycle of reflection, since previous strategic planning experiences did not prosper. From the interviewees' perception, the system enabled the organization to become aware of reality, detect and correct existing and, previously, unknown problems. Thus, it is possible to think of improvement actions. In addition, it was evident that communication permeated the entire process of PA, because it explained what was desired with the construction of metrics and directed the goal setting. These, encouraged the use of information for management and guaranteed timely feedback, allowing the comparison of the results obtained with those expected, defined by the goals set. This feedback provided the participation of all stakeholders, making it possible for the organization to verify the achievement of its strategic objectives, periodically feedback the system, reviewing its strategy, and reviewing its beliefs, behaviors and actions, making the organization more prepared for environmental changes. Finally, it can be concluded that learning is perceived by managers when they are able to show what the organization wanted to achieve, reflect on the adequacy of the objectives pursued and demonstrate that collaboration occurs in improving routines already developed in the organization. Also, when they are able to identify what is important to measure, parameterize the goals with these data, and provide feedback, in a way that makes it possible to analyze the results, comparing them with the established goals. And above all, when it is possible to trust information to guide decisions.
\end{abstract}

Keywords: Performance Management. Organizational learning. Generating elements of learning.

\title{
1 INTRODUÇÃO
}

A Avaliação de Desempenho Organizacional auxilia o aprimoramento das atividades das organizações (Amaratunga \& Baldry, 2002), oportunizando seu desenvolvimento. Historicamente, a avaliação tem se preocupado com a mensuração por meio da criação de indicadores para controle e monitoramento do cumprimento de metas em níveis estratégicos, táticos, operacionais e individuais (Brudan, 2010). Esses indicadores são responsáveis por implementar estratégias, ligando as ações organizacionais (Amaratunga \& Baldry, 2002; Oliver, 2009; Brudan, 2010); orientar comportamentos para alcançar desempenho satisfatório; e identificar quando e onde intervir e apoiar as decisões a serem tomadas (Amaratunga \& Baldry, 2002; Brudan, 2010; Canonico et al., 2015). Contudo, argumenta-se que, além de mensurar, os sistemas de Avaliação do Desempenho (AD) devem preocupar-se com a utilidade da informação à gestão (Amaratunga \& Baldry, 2002; Bititci, Garengo, Ates, \& Nudurupati, 2015).

Ainda, um sistema de avaliação bem estruturado fornece a comunicação clara de objetivos estratégicos (Amaratunga \& Baldry, 2002; Yeo, 2003b; Brudan, 2010; Canonico et al., 2015), gera informações necessárias para feedback (Buckmaster, 1999; Batac \& Carassus, 2009; Oliver, 2009) e, por meio deste, gestores revelam seus valores e preferências aos interessados na organização (Simons, 1990). Essa comunicação possibilita a observação dos objetivos estratégicos à cultura da organização (Oliver, 2009), tornando a AD importante à gestão da organização.

Contudo, é um desafio à gestão da organização desenvolver um sistema que lhe permita mensurar o desempenho, definir e esclarecer metas, alocar e priorizar recursos, orientar 
colaboradores e gestores e comunicar resultados de desempenho (Amaratunga, Baldry, \& Sarshar, 2000). Esses desafios impulsionam a busca de alternativas para mensurar e gerir o desempenho de uma organização que lhe promova controle do desempenho e, sobretudo, facilitar a aprendizagem para aperfeiçoamento contínuo.

A AD operacionalizada por mecanismos de Aprendizagem Organizacional (AO) permite às organizações coletar, analisar, armazenar, divulgar e usar informações relevantes (Oliver, 2009; Oyadomari, Pedrique, Bido, \& Rezende, 2014; Pekkola, Hildén, \& Rämö, 2015; Cucchi \& Barcellos, 2018). Prepara a organização para ser sensível às mudanças nos ambientes externo e interno (Amaratunga \& Baldry, 2002; Bido, Godoy, Araujo, \& Louback, 2010) e para revisar e reorientar os objetivos internos quando as mudanças no ambiente forem significativas (Amaratunga \& Baldry, 2002; Cucchi \& Barcellos, 2018).

$\mathrm{Na} \mathrm{AD}$, a AO tem o potencial de ajudar as pessoas e organizações a melhor compreenderem a relação entre o desempenho organizacional e o individual de forma holística (Brudan, 2010). Para isso, carece de sistemas de avaliação apropriados (Batac \& Carassus, 2009). Argumenta ainda que a existência de controles incentiva intercâmbio, distribuição de informações e conhecimentos entre colaboradores e líderes (Batac \& Carassus, 2009). No entanto, a função da AD deve buscar não apenas controlar, mas também aprender (Bititci et al., 2015), a fim de a organização incorporar os aprendizados para melhorar desempenhos individuais e organizacionais e contribuir para aperfeiçoamento da gestão. Somado a isso, argumenta-se que a AO é fundamental para sobrevivência e crescimento das organizações (Leitch, Harrison, Burgoyne, \& Blantern, 1996). Ela tem sido descrita como um processo de: detecção e correção de erros e solução de problemas (Argyris, 1977a; Senge, 1990; Kloot, 1997; Buckmaster, 1999); identificação e adaptação às mudanças ambientais (Argyris, 1977a; Senge, 1990; Kloot, 1997; Buckmaster, 1999; Bido et al., 2010); e desenvolvimento e melhoria de ações pelo conhecimento e compreensão da sua realidade (Oliver, 2009; Pekkola et al., 2015).

Com base nesse conhecimento, a AO, vivenciada, orienta ações para que a missão, os objetivos e as metas da organização sejam alcançados (Amaratunga et al., 2000; Amaratunga \& Baldry, 2002; Brudan, 2010) e garantam-lhe competitividade (Amaratunga et al., 2000; Shurafa \& Mohamed, 2016). Apresenta-se a oportunidade de discutir como foram alcançados os resultados passados, mas também se suas expectativas para o futuro continuam direcionadas às estratégias estabelecidas, bem como, feedback para suporte à tomada de decisões em todos os níveis da organização (Amaratunga \& Baldry, 2002; Canonico et al., 2015). Como apresentado, a aprendizagem traz muitos benefícios à organização.

Aponta-se que a aprendizagem ocorre quando uma unidade adquire conhecimento que reconhece como potencialmente útil para a organização (Buckmaster, 1999) e comunica claramente as ações e/ou comportamentos que os membros da organização devem perseguir ou evitar (Amaratunga et al., 2000; Bido, et al., 2010; Shurafa \& Mohamed, 2016), tornando-se um ciclo contínuo de experimentação (Senge \& Sterman, 1992), reflexão e ação (Yeo, 2003a; Pekkola et al., 2015). Senge e Sterman (1992) argumentam que a reflexão é o processo central da aprendizagem.

Com a reflexão, o aprendizado organizacional se desenvolve na compreensão das mudanças que ocorrem no ambiente externo e, em seguida, promovem adaptação de crenças e comportamentos para fazer frente a essas mudanças, com novas formas de pensar e de atitudes, e estabelecimento de novo padrão de comportamento (Yeo, 2003a; Bido et al., 2010). Assim, as organizações se ajustam à realidade e usam o conhecimento para melhorar o ambiente e se tornam mais flexíveis para se antecipar e responder às mudanças necessárias na direção estratégica (Simons, 1990; Amaratunga \& Baldry, 2002; Shurafa \& Mohamed, 2016) e demonstrar que estratégias e metas foram alcançadas (Buckmaster, 1999).

Contudo, a reflexão e a $\mathrm{AO}$ não são um processo coletivo, mas são desenvolvidas nos membros individuais (Leitch et al., 1996; Argote, 2011). As organizações só aprendem por meio da experiência e ações de indivíduos (Leitch et al., 1996; Oliver, 2009; Argote, 2011). O 
aprendizado individual envolve os processos de mudanças nas crenças (cognição), no comportamento e nas rotinas (Coad, 1996; Argote, 2011). O aprendizado organizacional requer aprendizagem individual, mas é influenciado por um conjunto mais amplo de variáveis sociais, políticas e estruturais. Envolve a partilha de experiências e conhecimentos, crenças ou pressupostos entre os indivíduos (Kloot, 1997; Oliver, 2009; Bido et al., 2010), para responder de forma positiva e criativa aos desafios, melhorar habilidades, dominar tarefas que realizam e desenvolver novas habilidades (Coad, 1996).

Além de envolver as pessoas (Amaratunga et al., 2000), seus conhecimentos e compreensão do contexto (Bititci et al., 2015), a AO se desenvolve no aprimoramento de processos, no desenvolvimento de sistemas de apoio e no fortalecimento da cultura da organização (Amaratunga et al., 2000). Para isso, a aprendizagem vivenciada pelo indivíduo deve ser disponibilizada na organização para que outros membros possam acessá-la (Argyris, 1977b; Argote, 2011). Dessa forma, o aprendizado será organizacional se possibilitar aquisição coletiva do conhecimento, modificar o comportamento da entidade (Batac \& Carassus, 2009), proporcionar melhoria contínua e incorporação desse conhecimento dentro da organização (Oliver, 2009).

Com base no exposto, percebe-se que a $\mathrm{AO}$ se desenvolve na $\mathrm{AD}$, manifestando-se na sua operacionalização, na utilização das informações na gestão e sendo utilizada para retroalimentação do sistema (Canonico et al., 2015). Esses processos melhoram as capacidades organizacionais que, somadas às experiências individuais, fazem com que a aprendizagem ocorra.

Assim, emerge a pergunta que norteia este estudo: como são percebidos, pelos gestores envolvidos, os elementos da AD na geração de AO? A fim buscar resposta a essa indagação, esta pesquisa tem por objetivo investigar a presença dos elementos da $\mathrm{AD}$ na geração de $\mathrm{AO}$, com base na percepção de pessoas envolvidas na concepção, implementação e retroalimentação do sistema de AD de uma organização.

Esta pesquisa é importante porque, baseada no construto teórico que aponta a AD como um elemento gerador de aprendizagem organizacional, pretende-se analisar a teoria na prática, focando na percepção dos envolvidos na concepção, uso e retroalimentação do sistema de AD. É original, pois propõe verificar a percepção dos elementos de $\mathrm{AD}$ e $\mathrm{AO}$ num estudo empírico, em uma organização que já tem um sistema de $\mathrm{AD}$ formalizado. É viável pelo acesso às pessoas a serem entrevistadas, proporcionado pela organização em estudo. Esta pesquisa delimita-se à realização de um estudo de caso único com entrevistas de pessoas envolvidas em concepção, uso e retroalimentação do sistema de $\mathrm{AD}$ utilizado pela organização, bem como a percepção e aprendizado vivenciado pelos entrevistados.

\section{REFERENCIAL TEÓRICO}

A AD tem por finalidade a implementação da estratégia organizacional (Bititci et al., 2015; Canonico et al., 2015). Nesse aspecto, promove aprendizado na organização, fundamentalmente pelo estabelecimento dos objetivos estratégicos (Amaratunga et al., 2000; Yeo, 2003b; Batac \& Carassus, 2009; Bititci et al., 2015). É função da AD construir métricas para mensurar os aspectos identificados, de modo a operacionalizar os objetivos estratégicos (Buckmaster, 1999; Amaratunga et al., 2000; Yeo, 2003b; Moynihan, 2005; Batac \& Carassus, 2009; Wouters, 2009; Bititci et al., 2015). Wouters $(2009$, p. 69) aponta que "as medidas de desempenho precisam se adequar ao contexto em que são usadas e não podem ser genéricas ou passar de uma organização para outra".

Isso é perceptível pela necessidade de alinhamento das métricas com a missão e visão da organização (Yeo, 2003a), logo as medidas devem refletir as especificidades da organização e, assim, permitem que ela tenha controle sobre resultados e rumos a serem tomados (Amaratunga \& Baldry, 2002; Bititci et al., 2015; Canonico et al., 2015; Shurafa \& Mohamed, 2016; Valmorbida \& Ensslin, 2016), com o monitoramento das métricas estabelecidas que verificam o alinhamento ou não à estratégia (Amaratunga et al., 2000; Batac \& Carassus, 2009; Bititci et al., 2015). Resulta dessa análise a reavaliação da estratégia (Amaratunga \& Baldry, 2002; Yeo, 2003a, 2003b; 
Canonico et al., 2015) e das métricas estabelecidas. Para isso, necessita que a organização reflita e analise as medidas de desempenho utilizadas (Yeo, 2003a; Wouters, 2009). Essa reflexão sinaliza o aprendizado experimentado pela organização (Yeo, 2002; Yeo, 2003a, 2003b).

A literatura aponta que a participação e o envolvimento de todos os interessados é outro fator que gera aprendizagem (Argyris, 1977b; Amaratunga \& Baldry, 2002; Yeo, 2003b; Argote, 2011). Sobretudo, o envolvimento dos líderes e dos altos executivos é primordial na concepção e implantação de sistemas de AD (Simons, 1990; Amaratunga \& Baldry, 2002), pois são eles quem legitimam os objetivos a serem perseguidos (Yeo, 2002). Entretanto, para que haja efetiva utilização do sistema e das informações geradas, deve-se viabilizar a participação de colaboradores (Bititci et al., 2015). Todos os membros de uma empresa devem ter a chance de participar, discutir e contribuir com as principais decisões políticas (Leitch et al., 1996), de compartilhar ideias, sugestões de ações a serem adotadas (Moynihan, 2005), além de transmitir a ideia que todos na organização são responsáveis pelo desempenho (Yeo, 2002; Yeo, 2003b).

Outro fator apontado como impulsionador da $\mathrm{AO}$ é a comunicação dos objetivos estratégicos, métricas e metas de desempenho (Argyris, 1977a, 1977b; Senge \& Sterman, 1992; Leitch et al., 1996; Buckmaster, 1999; Amaratunga \& Baldry, 2002; Moynihan, 2005; Brudan, 2010; Argote, 2011). Com ela, a organização evidencia aos colaboradores o que é considerado importante e os níveis de desempenho desejados (Yeo, 2002; Yeo, 2003a, 2003b; Oliver, 2009; Pekkola et al., 2015), direcionando esforços para o desenvolvimento de ações apropriadas ao alcance dos objetivos estratégicos (Leitch et al., 1996). Quando diferentes tipos de informações são compartilhados, reduzem-se os problemas de assimetria informacional na organização (Simons, 1990; Kloot, 1997), abrindo a possibilidade de promover diálogos contínuos e ordenados (Leitch et al., 1996) que permitem o aperfeiçoamento da gestão organizacional participativa.

Além da comunicação, o estabelecimento de metas na AD também produz aprendizagem à organização (Amaratunga \& Baldry, 2002; Moynihan, 2005; Batac \& Carassus, 2009; Brudan, 2010), pela definição de metas de desempenhos individuais ou coletivos que desafiem os indivíduos ao alcance dos objetivos (Oliver, 2009), ou pela reflexão para identificar padrões de desempenho ou metas a serem alcançadas (Pekkola et al., 2015).

A transparência e a responsabilização (Accountability) pela consecução dos objetivos estabelecidos (Amaratunga \& Baldry, 2002) também estão associadas à aprendizagem organizacional. Isso pode ser alcançado com o estabelecimento transparente de metas, objetivos e resultados esperados, evidenciando a lógica de funcionamento do sistema, os resultados esperados e os mecanismos de controle (Buckmaster, 1999; Yeo, 2002; Wouters, 2009). Isso possibilita ampliar a contribuição para o aperfeiçoamento do sistema na melhoria da coleta de dados, análise, armazenamento, disseminação e utilização de informações relevantes para a organização (Leitch et al., 1996; Moynihan, 2005). A retroalimentação na AD está relacionada à revisão periódica dos objetivos e critérios (métricas) que usam para mensurar o desempenho, ajustando ou redesenhando métricas (Buckmaster, 1999; Batac \& Carassus, 2009; Oliver, 2009; Wouters, 2009), testando a consistência dos sistemas, a fim de que eles contemplem seus valores, ou em resposta a mudanças ambientais (Buckmaster, 1999; Wouters, 2009; Bititci et al., 2015). Já a comparação de resultados na $\mathrm{AD}$ está relacionada à análise quanto aos resultados esperados em confronto com os resultados obtidos (Argyris, 1977a; Argyris, 1977b; Senge \& Sterman, 1992; Oliver, 2009), o desempenho real com o desejado (Shurafa \& Mohamed, 2016), com desempenho benchmarking (Batac \& Carassus, 2009) e ainda comparação com padrão aceitável e análise de variância do desempenho ao longo do tempo (Oliver, 2009; Canonico et al., 2015; Pekkola et al., 2015).

A aprendizagem também é desenvolvida na análise das métricas e no respectivo feedback sobre desempenho à gestão e aos colaboradores, coletando e analisando dados de resultados para apoiar a gestão, avaliar o quão bem a organização está progredindo em direção aos objetivos prédeterminados (Senge \& Sterman, 1992; Buckmaster, 1999; Amaratunga et al., 2000; Amaratunga \& Baldry, 2002; Moynihan, 2005) e também identificar pontos fortes e fracos e as áreas com 
desempenho aquém do esperado (Amaratunga \& Baldry, 2002; Bititci et al., 2015; Canonico et al., 2015; Valmorbida \& Ensslin, 2016).

A AD preocupa-se não só com o que está causando problemas, mas também com quais são as consequências dos desempenhos aquém do esperado e o que se pode fazer para aperfeiçoá-los (Oliver, 2009; Wouters, 2009), visando ao acompanhamento e ao alcance de metas individuais e organizacionais (Brudan, 2010), a tomada de medidas necessárias para aperfeiçoamento (Shurafa \& Mohamed, 2016; Amaratunga \& Baldry, 2002); sempre observando as mudanças que ocorrem no ambiente externo (Yeo, 2002). Na medida em que o ambiente passa por alterações, a organização deve se adaptar a essas mudanças, modificando seu comportamento para atender a demandas internas e externas (Kloot, 1997; Yeo, 2002), o que ocorre com adaptação de crenças e comportamentos, sobretudo com os objetivos e métricas da AD que, quando disseminados na organização, auxiliam na orientação dos comportamentos que devem ser seguidos e evitados (Shurafa \& Mohamed, 2016), direcionando e influenciando comportamentos em prol do alcance de desempenho adequado (Coad, 1996; Leitch et al., 1996; Canonico et al., 2015). A AO ocorre também na geração de informações que apoiem decisões (Kloot, 1997; Bititci et al., 2015; Valmorbida \& Ensslin, 2016), na utilização das informações para justificar as decisões tomadas e para direcionar as medidas de aperfeiçoamento formuladas, caso as metas não sejam cumpridas (Oliver, 2009; Valmorbida \& Ensslin, 2016), justificando o uso dos recursos; e na descentralização das decisões (Amaratunga \& Baldry, 2002), delega responsabilidades aos colaboradores.

Com base na análise feita, é possível afirmar que existe complementariedade/recursividade entre AD e aprendizagem ocorrida na organização. Ela se evidencia na comunicação, retroalimentação e revisão estratégica e em oportunizar a participação das pessoas (Valmorbida \& Ensslin, 2016).

Percebe-se que a $\mathrm{AO}$ permeia todo o processo de $\mathrm{AD}$, se desenvolve ao longo do processo e impulsiona a reflexão para retroalimentação do sistema. Em todas as etapas, pode-se aprender e aperfeiçoar processos com a aprendizagem ocorrida. Também contribui para que o sistema tenha aderência a longo prazo.

\section{METODOLOGIA}

A pesquisa segue uma abordagem metodológica interpretativista (Lukka \& Modell, 2010; Sampieri, Collado \& Lucio, 2013), que privilegia a percepção das pessoas, a visão ontológica de mundo e a subjetividade nas ações e decisões. Para capturar essa percepção, esta pesquisa utiliza entrevistas semiestruturadas para coleta de dados. Assim, tem enfoque qualitativo (Sampieri et al., 2013), pois este é selecionado quando se busca compreender a perspectiva dos entrevistados sobre os fenômenos.

Os dados são coletados por meio de técnicas pouco estruturadas e tratados por meio de análises de cunho interpretativo (Vergara, 2012). Logo, os resultados obtidos não são generalizáveis. As entrevistas semiestruturadas se baseiam em um roteiro de assuntos ou perguntas, e o entrevistador tem a liberdade de fazer outras perguntas para obter mais informações (isto é, nem todas as perguntas estão pré-determinadas) (Sampieri et al., 2013).

Cabe salientar que, na pesquisa qualitativa, o pesquisador se torna um instrumento de coleta de dados (Lukka \& Modell, 2010; Twining, Heller, Nussbaum, \& Tsai, 2016). Isso é perceptível durante a entrevista, na qual podem ocorrer insights para recompor o roteiro (Vergara, 2009), enriquecendo a coleta das informações, bem como na análise de dados, que envolve também a percepção do que as pesquisadoras viram e ouviram durante as entrevistas, e é guiada pelas interpretações do pesquisador (Alvesson, 2003; Lukka \& Modell, 2010).

A pesquisa foi desenvolvida por meio de entrevistas orientadas por Protocolo Ético de Pesquisa previamente analisado, discutido e acordado entre a organização e as pesquisadoras. Foi submetida à aprovação do Comitê de Ética em Pesquisa da Universidade de origem das pesquisadoras. Os dados coletados foram tratados de forma agregada, comparativa e informativa, 
sem mencionar o nome da organização e/ou dos participantes, que foram denominados no momento da transcrição como: "Entrevistado A"; "Entrevistado B" e "Entrevistado C", sem também a identificação de suas funções. Desse modo, pretende-se evitar qualquer prejuízo ou desconforto aos envolvidos na pesquisa. Todas as entrevistas foram gravadas para facilitar o registro, assim como garantir a fidelidade aos comentários feitos. Apenas as pesquisadoras tiveram acesso às entrevistas gravadas e às transcrições, assegurando a confidencialidade e o conteúdo discutido.

A escolha do local foi feita por conveniência e acessibilidade (Sampieri et al., 2013). Dentre as organizações conhecidas das pesquisadoras, buscou-se uma organização que já tivesse implantado um sistema de AD há algum tempo, pois carecia que já tivesse passado por todas as etapas: desenho, implementação, uso e retroalimentação. A amostra desta pesquisa foi realizada selecionando informantes-chave, que participaram das etapas de construção e revisão do sistema de AD. Após a aprovação da realização da pesquisa, solicitou-se à organização que indicasse uma pessoa envolvida ("Entrevistado A"). Este indicou um segundo ("Entrevistado B") e ambos citaram um terceiro ("Entrevistado C"). Com o aceite, foram agendadas as entrevistas previamente, as quais foram realizadas nas datas e locais estabelecidos pelos entrevistados.

\begin{tabular}{|c|l|l|}
\hline Entrevistado & Função & Estratégia $l$ \\
\hline A & $\begin{array}{l}\text { Colaborador responsável pelo desenvolvimento, } \\
\text { implementação e acompanhamento do sistema de AD. }\end{array}$ & $\begin{array}{l}\text { Indicado pela organização. } \\
\text { Citou entrevistado B e C. }\end{array}$ \\
\hline B & $\begin{array}{l}\text { Colaborador superior hierárquico do entrevistado A, } \\
\text { diretamente envolvido com a concepção do sistema de AD. }\end{array}$ & $\begin{array}{l}\text { Citado pelo entrevistado A e C. } \\
\text { Citou entrevistado A e C. }\end{array}$ \\
\hline C & $\begin{array}{l}\text { Consultor da metodologia utilizada para construção do } \\
\text { sistema de AD. }\end{array}$ & Citado pelo entrevistado A e B. \\
\hline
\end{tabular}

Figura 1. Lista de entrevistados e relação entre eles

Fonte: Elaborado pelas autoras.

Inicialmente, os participantes falaram sobre sua formação e experiência na organização e, em seguida, foram questionados sobre as questões propostas pelas pesquisadoras (roteiro previamente elaborado). Pela profundidade das respostas, estima-se que cada entrevista teve duração média de noventa minutos e todas foram gravadas. $\mathrm{O}$ agendamento das entrevistas foi aprovado pela organização de acordo com a disponibilidade dos entrevistados, para que não impactasse a normalidade das atividades dos participantes e da organização. Foi esclarecido aos entrevistados que eles tinham o direito de não responder quaisquer questões colocadas sem justificativas.

Após as transcrições, foi dada oportunidade aos entrevistados para ler a entrevista e fazer modificações nas respostas dadas, caso o transcrito pudesse deixá-los desconfortáveis. No entanto, isso não ocorreu.

As entrevistas foram realizadas com base no roteiro apresentado na Figura 2 e foram agrupadas pelo elemento de AD identificado como promotor de aprendizagem organizacional. Salienta-se que as perguntas foram elaboradas com base nos resultados dos trabalhos encontrados na literatura.

A coleta e a análise dos dados desta pesquisa são subjetivas (Twining et al., 2016). Serão analisadas as respostas apresentadas a cada uma das perguntas pelos entrevistados e confrontadas com a literatura de base, a fim de verificar se confirmam o que é apontado pela literatura ou não. Para isso, serão apresentados recortes de falas dos entrevistados. 


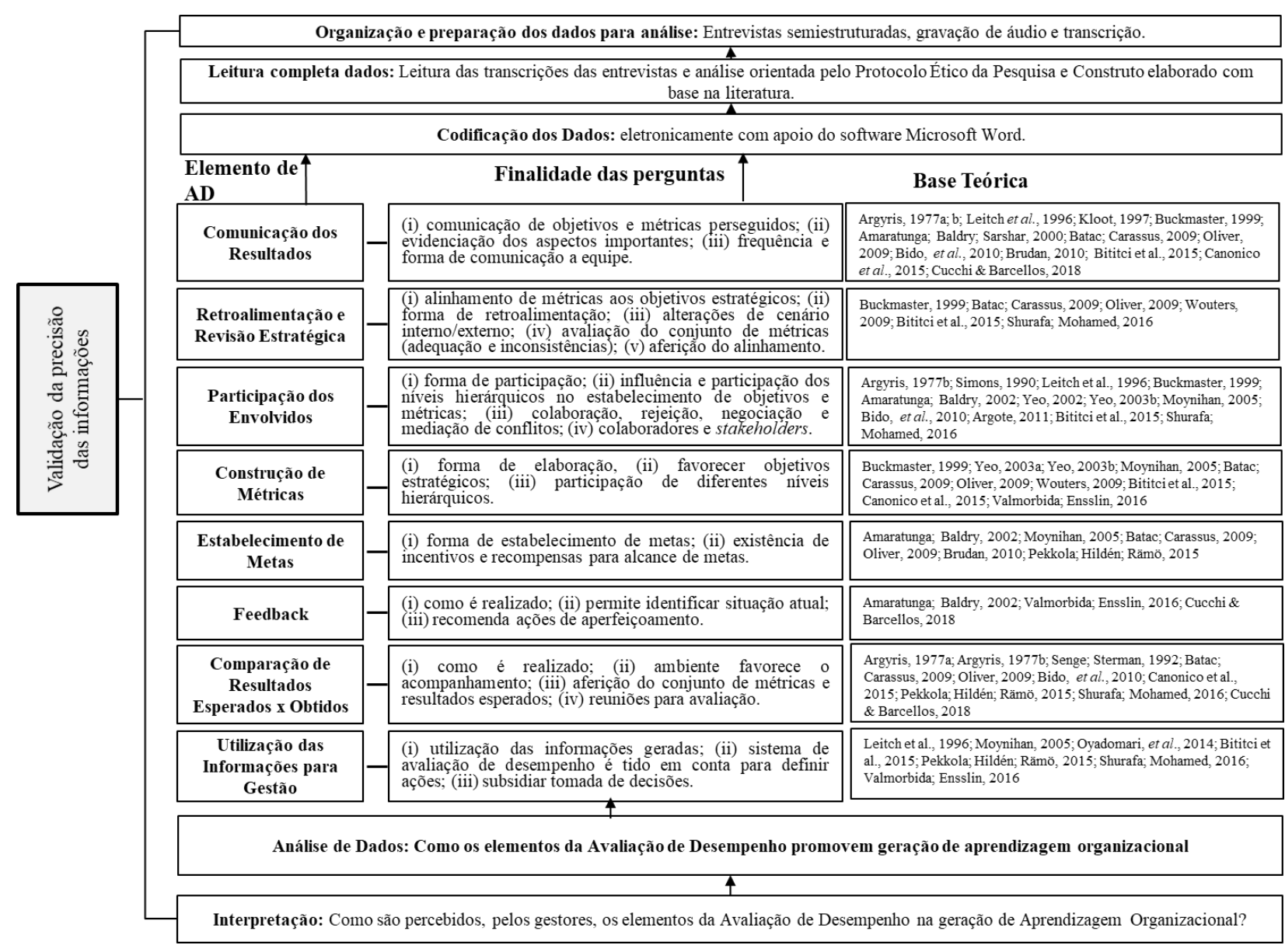

Figura 2. Construto da Pesquisa e Roteiro da Entrevista

Fonte: Elaborado pelas autoras.

Denzin e Lincoln (2006, p. 35) afirmam que, para garantia da validade científica de uma pesquisa qualitativa, devem ser observados os "critérios de fidedignidade, credibilidade, transferibilidade e confirmabilidade". Entende-se que a fidedignidade está na realização da transcrição integral das entrevistas/falas dos entrevistados e exposição no texto das falas que deram base para o entendimento, com a identificação do entrevistado. A confirmabilidade é assegurada na leitura posterior e aprovação. Garante-se a transferibilidade na medida em que o estudo pode ser repetido, obtendo-se resultados assemelhados, desde que os procedimentos para a coleta de dados sejam adotados (Yin, 2015). A adoção do protocolo do estudo de caso e a base de dados são fundamentais para determinar a credibilidade (Yin, 2015). Entendeu-se que o número de entrevistas foi suficiente para dar validade ao estudo, visto que os entrevistados eram as pessoas mais envolvidas no desenvolvimento e utilização do sistema de AD utilizado pela organização.

\section{APRESENTAÇÃO E DISCUSSÃO DOS RESULTADOS}

Os resultados aqui apresentados foram extraídos das entrevistas realizadas com gestores da organização, diretamente envolvidos com a concepção do sistema de AD. Não se pretende capturar a visão global sobre o fenômeno, mas, sim, entender como ele é observado por um grupo dentro da organização.

O primeiro aspecto interrogado foi sobre a comunicação dos resultados. Pelas falas, podese perceber que a comunicação é evidenciada para deixar explícito o que se quer e o que é considerado importante:

“A ferramenta que o gestor geral tem foi uma forma de deixar claro o que a organização 
queria acerca dos objetivos para a corporação e a forma de mensurar o alcance desses objetivos (...) Deixa transparecer que a organização tem objetivos, tem metas (...) A visualização do plano todo comunica mais fácil o que é importante, os objetivos perseguidos. Fica mais fácil de mensurar." (Entrevistado A)

"Quando a organização diz assim: 'isso aqui para mim é importante, você pode fazer o que quiser na tua unidade, mas isso aqui você tem que dar conta, esses cinco ou seis indicadores aqui. [sic] Esses eu vou cobrar. Você pode fazer outros tipos de ações, desenvolver outros programas, mas estes aqui eu quero que você observe'. Gerou convergência!" (Entrevistado B)

"O modelo fez com que eles enxergassem o que precisava fazer, orientou para identificar os aspectos humanos, equipamentos, mas, principalmente, em termos de atividade o que era requerido fazer." (Entrevistado C)

Ainda, esta comunicação incentiva e promove mudanças de comportamento:

"A organização queria incentivar determinadas atitudes dos colaboradores. Então, por exemplo, queria mudança de comportamento do colaborador, que antes não se comunicava não se comprometia em preencher o relatório de ocorrência. Queríamos que ele parasse e passasse a preencher dentro do modelo que foi estabelecido. Então, a gente colocou um indicador. E depois a gente descobriu que o modelo MCDA (Multicriteria Decison Aiding) ele te favorece à mudança de comportamento. Você sai de uma situação atual (...) você consegue definir qual a situação futura que você quer e fazer com que as pessoas vão indo para lá." (Entrevistado B)

Quanto à forma como é feita essa comunicação, os entrevistados apontam que as informações são disponibilizadas pelo sistema.

"Eles têm acesso lá diariamente no sistema, podem acessar e ter a informação, da mesma forma que eu te mostrei aqui." (Entrevistado A)

Apontaram também que a forma inicial, para mostrar que foram adotados novos procedimentos, foi informar a importância das ações que necessitavam ser desenvolvidas:

"No início o modelo era focado em atender a necessidade do decisor. Ele estava convencido que seria bom. A partir daí ele começou a fazer um trabalho de convencimento. 'Vamos ver como que está o desempenho, se está bom, se está ruim'. Isso foi explicitado logo de cara, essa ferramenta não é para pegar no pé de ninguém. Só que nós queremos que vocês passem a se preocupar (...) e direcionem os esforços de vocês para atender isso aqui que a gente está considerando importante.” (Entrevistado B)

É possível afirmar que o sistema de AD possibilitou comunicar os aspectos importantes e direcionar comportamentos para alcance das metas estabelecidas. Foi uma forma de aprendizagem: para o gestor que possibilitou incluir no sistema de $\mathrm{AD}$ aquilo que ele achava que era importante em termos de objetivos estratégicos e metas, e desta forma tornou-se fácil verificar se elas foram atingidas; e para os colaboradores, pois visualizam como ações diárias impactam o alcance dos objetivos importantes.

A retroalimentação na $\mathrm{AD}$ está relacionada à revisão periódica dos objetivos e critérios (métricas) que são usados para mensurar o desempenho, ajustando ou redesenhando métricas. Quanto a isso, os entrevistados relatam que a organização teve várias experiências anteriores de planejamento estratégico, que acabavam sendo ineficazes porque não envolviam reflexão interna 
sobre adequação e aplicabilidade das métricas. Nota-se ainda que atribuem aos processos da metodologia utilizada parte da razão de sucesso na aprendizagem:

"Vislumbrou que seria uma metodologia interessante que a organização viesse a utilizar para fazer o seu planejamento estratégico. Nós já havíamos feito três experiências de (...) planejamento estratégico. E a dificuldade que a gente encontrou nestas três experiências foi a de poder transpor o planejamento estratégico para a prática. É uma coisa complicada você definir as diretrizes estratégicas. Fazer o plano estratégico é a coisa mais fácil que tem, mas acaba não tendo a aplicabilidade prática porque não tem como controlá-lo. Então você cria planos, indicadores, diretrizes, desdobra em ações, indicadores, mas não consegue controlar porque você não tem como medir. Então essa era a angústia que a gente tinha na época. E então como chefe da organização, tomando conhecimento da metodologia, ele viu que ali estava o link que a gente precisava, a metodologia podia complementar aquilo que a gente já tinha tentado no passado, mas que não tinha conseguido fazer." (Entrevistado B)

Apontam que o sistema de $\mathrm{AD}$ implementado conseguiu operacionalizar o planejamento estratégico:

"Os indicadores que nós estamos medindo fazem parte do plano estratégico. Nós temos um documento chamado de plano estratégico e ele é composto por uma missão, visão, diretrizes estratégicas, e todos os demais indicadores estão alinhados. Nós temos feito um processo de validação disso a cada dois anos. Então, por exemplo, em alguns projetos, alguns indicadores que tratavam de projetos muito pontuais e que a gente conseguiu atingir os $100 \%$ de excelência, não tinha mais o que melhorar, porque o projeto se esgotou. Daí nós retiramos. E surgiram outros, por exemplo, o mobile. Quando a gente iniciou (...) nem imaginou que poderia ter que construir o projeto." (Entrevistado B)

Com base na operacionalização do planejamento estratégico, o sistema passou a ser algo presente e útil para a organização, e esse aprendizado possibilitou verificar quais aspectos não estavam adequados/alinhados e quando era necessário rever o sistema:

“A gente entendeu que não seria oportuno rever o plano sem estabelecer um plano estratégico para a organização que não esteja (...) ou não estivesse alinhado com o plano de desenvolvimento do Estado. E essa revisão do plano estratégico vai trabalhar para alinhar o plano estratégico, com os processos que a organização executa e com o orçamento, alocando recurso para aquilo que é importante.” (Entrevistado A)

Analisando as falas dos entrevistados, o aprendizado gerado na experiência do sistema de AD possibilitou operacionalizar os objetivos estratégicos, e a retroalimentação permitiu visualizar os aspectos desalinhados que necessitariam de aperfeiçoamentos, o que impulsionou a revisão do sistema e dos objetivos e metas constantes no plano estratégico.

A participação de todos, líderes e colaboradores, fez com que o aprendizado proporcionado pelo sistema de $\mathrm{AD}$ fosse compartilhado de modo a se tornar institucional. Tendo alterado o gestor geral, houve alterações nos indicadores, mas a lógica de funcionamento do sistema foi mantida.

Pelas falas, é oportunizado a todos os níveis hierárquicos da organização participar.

"E todos os níveis hierárquicos podem participar desse processo. Nesse momento em que são feitas as revisões na consulta via gestor de área, a gente depende da capacidade do gestor local que recebe essa demanda de ele socializar isso na sua unidade, né? A gente acaba tendo pouco controle a respeito disso. Se um cara recebe lá e não transmite de forma 
adequada, não oportuniza às pessoas terem acesso.” (Entrevistado A)

Afirmam que inicialmente, quando da construção do modelo, não houve ampla participação. Um grupo foi capacitado para desenvolver o sistema de $\mathrm{AD}$, estabelecendo objetivos estratégicos e operacionalizando-os por meio dos indicadores e metas de desempenho.

"No início não houve. Houve a vontade do decisor que escolheu os colaboradores que estavam habilitados, para poder construir, depois foi ao conselho estratégico. Foi apresentado e aí sim colheram-se sugestões. Quem basicamente tem utilizado muito essa ferramenta são os colaboradores do nível tático, que é uma ferramenta de gestão, o colaborador da 'ponta' pouco usa. Então quem vai utilizar é o gestor geral. O gestor de operações utiliza para fazer planejamento. E para chegar à ponta nós temos documentos internos, que são as ordens de operação, as ordens de serviço." (Entrevistado B)

"Não participaram da construção inicial. Depois quando o sistema começou a funcionar e operacionalizar o sistema eletrônico, os intervenientes começaram a tentar influenciar." (Entrevistado C)

Reconhecem que há outras formas de promover a participação que poderiam ser adotadas, mas que até o momento não foram.

"Então é só no momento que a gente tem a primeira versão já pronta. Na verdade, eles não participam do processo de construção dos objetivos, porque a gente tem dificuldade muito grande em termos de metodologia para fazer isso, né? Estamos falando de uma organização de 10 mil pessoas. Claro que certamente teriam outras formas, poderíamos fazer seminários etc., mas a forma com que a gente achou de estar oportunizando é quando tem a primeira versão pronta disponibilizar para as unidades darem feedback em cima." (Entrevistado A)

O envolvimento também foi estimulado pela mudança de rotinas de trabalhos necessárias para alimentação do sistema. Com base na implementação, houve um trabalho de convencimento da importância da participação e da alimentação dos dados e uso do sistema.

"Então assim a gente tentou incutir (...) A gente percebeu que fazer isso por imposição é complicado. Então a gente trabalhou pelo convencimento. Tem unidades que estão muito mais avançadas. Que tem isso como (...) referencial, que acompanham isso aqui. Outras menos. Outras muito menos. Mas a gente acredita aqui que foi um negócio que entrou na cultura, na rotina. Então nesses seis anos teve aprendizado. Principalmente porque a gente acabou de fazer um trabalho agora de construção da cadeia de valor da organização." (Entrevistado A)

Reconhecem que a participação começou a ser mais efetiva quando envolveram os colaboradores na definição de ações necessárias para o alcance das metas definidas pelo alto escalão.

"Então, antigamente [o gestor geral] tinha uma lógica. Estabelecia aqui os planos a serem executados na ponta. Daqui ele dizia: 'Tu vai fazer isso, isso e isso [sic]. Pô! Como é que? isso se não tem conexão nenhuma. Qual o meu problema com a realidade?'. Então, agora, a gente estabelece o objetivo, estabelece a meta. E as ações para poder alcançar a meta são estabelecidas no nível local." (Entrevistado A)

Ainda é bem presente nas falas dos entrevistados que a participação é oportunizada nas revisões do sistema, e os interlocutores são os gestores de área. As sugestões apresentadas são avaliadas pelo gestor geral e, frequentemente, incorporada ao modelo/sistema. 
"Mas aqui especificamente quando tem as revisões, ao longo do processo, são colhidas sugestões e para alterações na próxima revisão. E durante a revisão tem aquele momento em que a gente oportuniza o pessoal poder está olhando [sic]." (Entrevistado A)

"Em cada revisão. Antes da gente fechar (...) a gente faz a versão, valida junto ao conselho estratégico. Antes de publicar e dizer que é isso, a gente encaminha para todos os comandos. Aí, a organização tem atribuição de reunir os seus colaboradores, disseminar entre os colaboradores. Se tiverem alguma contribuição, alguma consideração, algum questionamento a fazer, fazê-lo. E a gente, efetivamente, durante esse processo recebeu feedbacks, questões que acabaram sendo incorporadas no plano. Então a gente não faz a publicação sem antes oportunizar para que eles possam estar dando uma contribuição [sic]. E esse processo acontece mesmo com o plano já publicado. Se eles têm um feedback, tem considerações que acabam não sendo incorporadas naquele momento, mas que vão ser analisadas na próxima revisão." (Entrevistado A)

Um fator importante apresentado é o comprometimento dos líderes e o engajamento que ele conseguiu da equipe. Como apontado pelo entrevistado C, "Que eu saiba não houve nenhum tipo de incentivo para prestigiar o modelo. $\mathrm{O}$ modelo se justificava em duas formas: os seus resultados e o comprometimento dos seus líderes".

Outro aspecto apresentado foi a renovação do quadro de colaboradores e as trocas dos gestores gerais ocorridas durante o período.

"Na medida em que o pessoal foi impactado, em que o pessoal foi entrando na organização já com uma cabeça nova, já foi recebendo essa informação lá no banco escolar, para que ele que está recebendo informação lá, não vai mais achando surpresa (...) Já é o padrão e para esse 'mais velho' o padrão é outro. Ele vai ter que se adaptar, vai ter que sair da zona de conforto, deixar de fazer o que fazia e faz bem, muitas vezes, para se adaptar ao novo contexto, ao novo 'paradigma' e isso, para aqueles que são mais desprendidos gera oportunidade de ter um avanço muito grande, mas para aqueles que são mais receosos, isso acaba gerando desconforto.” (Entrevistado B)

"Ter mudado o gestor geral da organização... que em um órgão público o risco é muito grande de você ter toda uma 'disruptura' acerca do que vinha sendo feito por se atrelar à pessoa do gestor anterior, né? E nós tivemos a felicidade de mudar o gestor e manter a lógica. Tanto que a segunda revisão já [está] no âmbito de outro comando." (Entrevistado A)

Observa-se a construção de métricas que possibilitou o aprendizado à medida que eles entenderam que, fazendo de forma clara e integrada aos objetivos perseguidos, seria mais fácil envolver as pessoas a colaborarem com o sistema avaliativo. Assim procederam os funcionários.

Os entrevistados apontam que investiram bastantes esforços para pensar nos indicadores, refletir sobre como mensurar os aspectos que respondessem pelos objetivos estratégicos: "A gente sabe que quando eu estabeleço o indicador, eu direciono a missão e esforço." (Entrevistado A)

Refletiram também sobre como e por que mensurar os objetivos:

"Hoje, por exemplo, o plano estratégico trabalha com a lógica que a organização define o que, quanto e qual é o objetivo, e oportuniza a participação da ponta, mas quem quer ver o resultado é o decisor. Então define os objetivos e o quanto... ou seja, a meta e os indicadores, a forma de mensuração e as bases de dados que alimentam cada indicador, para deixar bem transparente a taxa, o efetivo da unidade. Tem indicadores que eu uso que usam a informação do número de pedido. Qual é o valor absoluto que eu uso? Porque essa taxa de 39,5 se refere a ocorrências no período de doze meses, né? O como, as ações (...) é 
a comunidade que vai operacionalizar aquele objetivo, é uma construção local." (Entrevistado A)

Ainda, preocuparam-se em informar quais as bases que alimentavam o sistema para tornar mais claro o entendimento e dar credibilidade e confiabilidade ao processo:

"Na composição do plano, nós tomamos o cuidado de não gerar descrédito em relação a tudo aquilo que tinha sido feito historicamente. Então, nós aproveitamos muito na construção, na estruturação do problema e na definição das questões principais do plano, nós aproveitamos os planos anteriores. Então a gente já tinha uma história, e o que se decidiu na época: "Não vamos jogar isso fora". A gente aproveitou o que já tinha e a partir daí começamos a construir todos os indicadores, a árvore de estrutura." (Entrevistado B) "Foi posto isso muito com calma. Quando você coloca indicadores, a primeira reação das pessoas é: 'Opa! Estão querendo me controlar, então eu sou contra!'. Controlar significa que em algum momento você está sujeito a ser punido. O gestor geral então chamou uma reunião com todos os gestores de área explicando que a intenção não era controlar ninguém, que era apenas direcionar esforços para que todo mundo pensasse em uma mesma direção. Que aqueles que estivessem em dificuldade, ou que aparecessem com uma dificuldade ali, a gente iria dar suporte. Por que eu não atingi o índice em redução a determinada ocorrência? Será que está faltando efetivo para mim? Será que está faltando estrutura? Será que há influência de algum fator externo? Então a primeira forma de fazer isso foi através de conversa de convencimento do uso da ferramenta, principalmente para alta cúpula, né? Ele sabia que aquele Business Intelligence (BI) e aquelas informações ele poderia utilizar para medir o desempenho e junto com aquilo ali ele poderia ter as informações básicas do que acontecia." (Entrevistado B)

Dessa forma, evitaram desconfianças quanto aos resultados apresentados, evidenciando as bases de onde eram colhidos os dados responsáveis pelas informações do desempenho alcançado, e, sobretudo, estavam acessíveis a eles, para melhorar os resultados.

Verificou-se, em relação ao estabelecimento de metas, a mesma preocupação com a credibilidade do sistema em relação a estabelecer metas alcançáveis e também a desafiar os colaboradores, bem como a evidenciar a lógica de funcionamento do sistema, os resultados esperados e os mecanismos de controle adotados:

"Outra coisa, essa ideia do local eu consigo planejar minha unidade, né? Com as metas as coisas... por mais que eu não possa fugir do indicador, aqui [posso planejar] quanto que seriam as metas, [quanto] as pessoas podem contribuir, né?" (Entrevistado A)

"Antes, nós ouvíamos: 'Pô, mas o que é isso? De onde tiraram nossa meta? Isso é impossível! Qual dado usaram? Está errado. Está errado!"” (Entrevistado B)

"Você tem sempre como explicar a meta. Porque a pessoa pergunta: "De onde é que vem esse número? De onde vocês tiraram isso?”. Então, essa questão de você saber explicar qual foi o referencial de desempenho que foi estabelecido é fundamental. A pessoa pode questionar, pode dizer que tem outros [números]? Pode. Mas pelo menos aquele que foi estabelecido, tem um motivo, né?." (Entrevistado A)

Esse estabelecimento de metas não era visado apenas para demonstrar que estava bem, mas para garantir que os colaboradores não se acomodassem e continuassem buscando melhoria contínua:

"Nos indicadores de resultado (...) Eu tenho uma meta Estadual, mas eu tenho metas regionais. Esta foi uma inovação que a gente fez nessa revisão do plano aqui. Para fazer 
mais sentido, para cobrar mais, para estabelecer metas razoáveis. Assim ao mesmo tempo, a meta (...) tem que exigir esforço, mas não pode ser algo que seja inalcançável ou (...) uma coisa tão fácil que o cara não precisa fazer nada que está bem. E nos planos anteriores a meta era estadualizada. (...) Então regiões mais complicadas quando estabeleciam a meta Estadual, por mais que o cara fizesse, o cara jamais alcançaria aquela meta ali no prazo. (...) [Já em] regiões do Estado que são tranquilas, o cara "navegava" frouxo. Aí então a gente optou por esses indicadores de resultado, estabelecer por região. Então tem meta para a organização como um todo, mas cada região é cobrada por uma meta de acordo com a sua realidade." (Entrevistado A)

"A gente foi extremamente rigoroso na calibragem. $\mathrm{O}$ 'indicador $\mathrm{n}^{\circ} 1$ ', a gente resolveu (...) acompanhando uma tendência internacional (...) aumentar isso, para envolver mais aspectos. E nos colocamos como neutros, [e foi] nosso melhor desempenho nos últimos cinco anos. Então, para a gente conseguir sair para o nível de mercado, nós precisávamos empatar com o nosso melhor desempenho histórico. E para partir para o nível de excelência, nós utilizamos o índice da Organização das Nações Unidas (ONU), que é de dez por 100 mil habitantes, para chegar lá vai ter que ralar muito. Depois a gente fez uma adaptação na calibragem para a questão regional". (Entrevistado B)

Percebeu-se pelas falas dos entrevistados que houve aprendizado em relação às metas, tanto no ajuste do seu estabelecimento quanto na credibilidade de informações para alimentar o sistema e indicar o cumprimento das metas. Na percepção dos entrevistados, esse aspecto foi o que fortaleceu a colaboração das pessoas para seu alcance.

Quanto ao feedback, os entrevistados afirmaram que a AD implantada possibilitou ter e dar feedback em tempo real, pois, com o acesso ao sistema, é possível acompanhar:

“O gestor geral tem a informação sobre quais são as unidades que estão (...) puxando o desempenho para baixo. Então ele verifica que esses dois estão no verdinho, outro no amarelo, e esse aqui tá no vermelhão, bem no vermelho." (Entrevistado A)

"E, aí, aqui a ferramenta mobile permite medir quase todo o processo de gestão da gestão da informação? Coleta, registro, processamento, análise e apresentação dos resultados, que você compara com as métricas que foram estabelecidas. No primeiro momento, houve dificuldade com a inovação. Quando a gente começa [a]difundir, reduz." (Entrevistado B)

Pelas falas de ambos os entrevistados (A e B), é apontado que, no início, o feedback era coercitivo, focava mais o controle, depois passou a focar mais o que estava acontecendo, entender o porquê daquilo, visando aperfeiçoar, incorporando assim o aprendizado:

"O feedback (...) no começo tinha mais essa cultura, de pegar o telefone e ligar cobrando. Depois disso foi deixado um pouco de lado. Então a gente tinha reuniões onde era colocado lá o desempenho de uma unidade, chamava o gestor de área da unidade lá na frente para explicar o que estava acontecendo." (Entrevistado A)

"Depois surgiu um mecanismo de controle, foi mais burocrático do que a coisa controlada e aí a gente meio que deixou isso de lado (...) Porque a gente fez acompanhamento. Então, de vez em quando, a gente entra, com certa periodicidade, vai olhando o que está acontecendo e vai interferindo com o pessoal." (Entrevistado B)

O Entrevistado C entende que o processo de feedback tem dado certo e funcionado na organização. No entanto, lembra que, nas revisões do sistema, seria necessário um olhar externo sobre o modelo todo:

"E este processo de retroalimentação é indispensável para o processo de evolução, mas tem que ter um feedback com conhecimento alicerçado, (...) utilizando a técnica Delphi, isso 
é, por um grupo de pessoas que são experts para validação, e colocando em discussão, e a partir dessa discussão, uma boa liderança faria com que este grupo convergisse em termos de próximas etapas de evolução do modelo." (Entrevistado C)

A comparação de resultados na $\mathrm{AD}$ está relacionada à análise quanto aos resultados esperados em confronto com os resultados obtidos, o desempenho real com o desejado. Quanto a isso, foi exposto que, da forma como foram estabelecidos os indicadores, estes propiciam a comparação em tempo real:

"Principalmente para os indicadores de resultados da atividade a gente trabalha com taxa, com o número daquele evento por 100 mil habitantes nos últimos doze meses. Cada objetivo tem as faixas de desempenho e aqui nesse geral é a meta estadual. Então a gente percebe em que a gente está patinando e o que conseguiu atingir. A gente conseguiu dar uma melhorada, conseguiu estabelecer referenciais de desempenho interessantes, então aqui está vivo. E aí é legal porque cada unidade, por exemplo, cada um vê o seu desempenho." (Entrevistado A)

"São em vários níveis, né? Tanto no nível operacional quanto no estratégico cada um olha o que lhe diz respeito e verifica a situação, o que tem que fazer para chegar [ao seu objetivo] ou se está no nível bom ou não." (Entrevistado B)

No sistema, foi criada sinalização de níveis de referência: vermelho para desempenho abaixo da meta mínima aceitável; amarelo para os considerados competitivos; e verde para desempenhos considerados excelentes e superiores às metas estabelecidas:

"Mas para a região dele, esse valor aqui é ruim, (...) [isso] foi o que permitiu a regionalização da meta. Permitiu verificar (...) esse desempenho, aqui ele estaria no nível de excelência. Só que daí para região, não reflete a realidade deles" (Entrevistado A)

"Muitas vezes há alguma reprimenda. a gente olha lá o camarada vem piorando, piorando, piorando, piorando (...). [A situação] Não [é] institucionalizada, é mais pessoal, principalmente quando você percebe que a unidade está totalmente divergente. Então você identifica essas diferenças e a ferramenta ajuda a chamar atenção e colocar os pingos nos "is"” (Entrevistado A)

"Na MCDA que construímos, ele mostra se subiu ou desceu. Opa! Piorou. O que vai me dizer tem referência, né? O que vai me dizer, o que tá acontecendo, são as informações que alimentam ele e aí a ferramenta funciona bastante. Legal que a mesma informação eu tenho, que me diz que dá: no dia tal, hora, as circunstâncias, o gráfico do impacto daquilo lá. Então, na verdade, eu tenho vinte ocorrências, o pontinho lá daquela escala, o indicador do MCDA... Eu vou botar o BI, ele vai me dizer que horas aconteceram os vinte, vai demonstrar os vinte, destrinchá-los em diversos aspectos, que você tem mais informações para poder entender. Como é que eu faço para evitar?" (Entrevistado B)

Quando perguntados sobre a utilização das informações para gestão, todos os entrevistados confirmam que o sistema de AD só está funcionando porque ele subsidia as decisões a serem tomadas e verifica o alcance dos objetivos. Pelas falas, percebe-se que a utilização das informações é algo incorporado no dia a dia da organização:

"Hoje serve muito mais como um referencial para a própria unidade acerca do desempenho dela (...) Mesmo passados seis anos a gente está aprendendo ainda. Tem muitas outras unidades nossas que incorporaram isso. (...) [Tem] reunião, as pessoas comentam, abrem o sistema e mostram. Eu consigo ver o status quo do que é mais observado e o mais importante para nós, que é resultado." (Entrevistado A) 
A aprendizagem ocorre também na geração de informações que apoiam a decisão na utilização das informações para justificar as decisões tomadas e para direcionar as medidas de aperfeiçoamento formuladas, caso as metas não sejam cumpridas:

"A parte de acompanhamento disso, de cobrança dos resultados, acompanhamento, controle e cobrança, acho que ainda é um grande gap. Apesar das facilidades da ferramenta, acho que ainda não está incorporado na cultura. (...). Mas eles têm acesso e frequentemente acessam. (...) Várias vezes aparecem matérias no site da organização e o cara diz: 'melhoramos', e aparece uma tela do gráfico do plano estratégico aqui. Às vezes você vai a reuniões, o camarada começa a dizer que melhorou tal coisa e mostra aquele gráfico que ele viu aqui e foi para lá." (Entrevistado A)

"Ele mostra as consequências e apoia as tomadas de decisões." (Entrevistado C)

Embora reconheçam que as informações geradas pelo sistema ainda podem ser mais exploradas e trazer mais benefícios para a organização e para a melhoria do trabalho:

"Nossa expectativa é que as gerações que vêm trabalhando no nível tático não desistam e que ela se consolide como uma ferramenta de tomada de decisão mais robusta. Vai contribuir para a ferramenta ser mais utilizada no dia a dia das decisões né. Mas confesso que ela é menos utilizada do que deveria." (Entrevistado A)

Quando perguntados sobre o que acredita que seria diferente na gestão se não houvesse o sistema como referência, afirmam que

“Certamente se não tivesse aqui, 'a máquina' continuaria girando. Não sei se os resultados seriam melhores ou piores, mas certamente a gente continuaria trabalhando só que sem referencial, sem saber se estava alcançando objetivo." (Entrevistado A)

“Antes, tínhamos os dados, mas não eram organizados. Às vezes não tinha, às vezes não estava registrada, às vezes teria que criar um sistema para poder registrar aquela informação. Que foi possível pela organização proposta pelo MCDA-C e a operacionalização do mesmo via BI.” (Entrevistado B)

Houve incentivos para que as pessoas passassem a se preocupar com os resultados apresentados pelo sistema, esse motivo direcionou esforços para que ele fosse considerado importante e recebesse colaboração:

"Começou a cobrar daí, a exigir, a controlar, e as pessoas pelo menos [a] começar [a] acessar o BI, para acompanhamento daquilo. Depois ele tomou uma iniciativa de todo gestor de área, quando vinha conversar com ele, pedia para abrir o BI na frente dele. Então pegava os indicadores mais afetos à área dele. 'Como está o teu desempenho?' Observar se subiu, desceu, subiu ou desceu. Então a gente começou a fazer efetivamente gestão estratégica, a partir da metodologia e da ferramenta. Se não tivesse a ferramenta, não teríamos conseguido fazer. Ia ter muito mais dificuldade para fazer." (Entrevistado B) "Nós fizemos dois ou três treinamentos. Nós trouxemos todos os chefes de planejamento operacional de todas as unidades e fizemos dois dias aqui. Passamos as ferramentas, mostramos para eles a importância. (...) Daí não é mais feito de forma intuitiva. Tem um amparo. Passa a ser feito com direcionamento estratégico." (Entrevistado B) 
Todos os entrevistados apontam que o sistema é utilizado na gestão. Se não fosse assim, não haveria razão de a organização ter a ferramenta, e certamente teria sido mais uma experiência de insucesso.

A Figura 3 resume os achados dessa pesquisa acerca de como são percebidos pelos gestores os acontecimentos durante o processo de avaliação de desempenho e que, segundo a literatura de base, evidenciam o desenvolvimento da aprendizagem organizacional.

\begin{tabular}{|c|c|c|}
\hline Elemento AD & Recorte da entrevista & $\begin{array}{l}\text { Como é percebido } \\
\text { pelos gestores? }\end{array}$ \\
\hline $\begin{array}{l}\text { Comunicação dos } \\
\text { Resultados }\end{array}$ & $\begin{array}{c}\text { "forma de deixar claro o que a organização queria" } \\
\text { "organização diz assim: "isso aqui para mim é importante" } \\
\text { "enxergassem o que precisava fazer" } \\
\text { "queria mudança de comportamento do colaborador" } \\
\text { "visualizam como ações diárias impactam o alcance dos objetivos importantes" }\end{array}$ & $\begin{array}{l}\text { Evidenciar o que a } \\
\text { organização desejava } \\
\text { atingir }\end{array}$ \\
\hline $\begin{array}{l}\text { Retroalimentação e } \\
\text { Revisão Estratégica }\end{array}$ & $\begin{array}{c}\text { "transpor o planejamento estratégico para a prática" } \\
\text { "indicadores que nós estamos medindo fazem parte do plano estratégico" } \\
\text { "alinhar o plano estratégico com os processos que a organização executa e com o orçamento. Alocando } \\
\text { recurso para aquilo que é importante" }\end{array}$ & $\begin{array}{c}\text { Refletir sobre a } \\
\text { adequação dos } \\
\text { objetivos perseguidos }\end{array}$ \\
\hline $\begin{array}{l}\text { Participação dos } \\
\text { Envolvidos }\end{array}$ & $\begin{array}{l}\text { "todos os niveis hierárquicos podem participar" } \\
\text { "a vontade do decisor que escolheu os colaboradores que estavam habilitados, para poder construir, } \\
\text { depois foi ao conselho estratégico" } \\
\text { "as ações para poder alcançar a meta são estabelecidas no nivel local" } \\
\text { "o modelo se justificava em duas formas: os seus resultados e o comprometimento dos seus líderes" }\end{array}$ & $\begin{array}{l}\text { Demonstrar que a } \\
\text { colaboração se dá em } \\
\text { aperfeiçoar rotinas já } \\
\text { desenvolvidas na } \\
\text { organização } \\
\end{array}$ \\
\hline $\begin{array}{l}\text { Construção de } \\
\text { Métricas }\end{array}$ & $\begin{array}{l}\text { "quando eu estabeleço o indicador, eu direciono a missão e o esforço" } \\
\text { "define os objetivos e o quanto, ou seja, a meta e os indicadores, a forma de mensuração e as bases de } \\
\text { dados que alimentam cada indicador, para deixar bem transparente, a taxa, o efetivo da unidade" } \\
\text { "indicadores eram para direcionar esforços para que todo mundo pensasse em uma mesma direção" }\end{array}$ & $\begin{array}{l}\text { Identificar o que é } \\
\text { importante mensurar }\end{array}$ \\
\hline $\begin{array}{l}\text { Estabelecimento de } \\
\text { Metas }\end{array}$ & $\begin{array}{c}\text { "tem meta para organização como um todo. Mas cada região é cobrada por uma meta de acordo com a sua } \\
\text { realidade" } \\
\qquad \text { "cobrar mais, para estabelecer metas razoáveis" }\end{array}$ & Parametrizar as metas \\
\hline Feedback & $\begin{array}{c}\text { "quais são as unidades que estão puxando o desempenho para baixo" } \\
\text { "coleta, registro, processamento, análise e apresentação dos resultados" } \\
\text { "no começo tinha mais essa cultura, de pegar o telefone e ligar cobrando" } \\
\text { "depois surgiu como um mecanismo de controle" }\end{array}$ & $\begin{array}{l}\text { Instrumentalizar o } \\
\text { feedback }\end{array}$ \\
\hline $\begin{array}{l}\text { Comparação de } \\
\text { Resultados } \\
\text { Esperados x Obtidos }\end{array}$ & $\begin{array}{l}\text { "compara com as métricas que foram estabelecidas" } \\
\text { "tanto no nível operacional quanto no estratégico, cada um olha o que lhe diz respeito e verifica a } \\
\text { situação, o que tem que fazer para chegar ou se está no nível bom ou não" }\end{array}$ & $\begin{array}{l}\text { Analisar os resultados } \\
\text { com as metas } \\
\text { estabelecidas }\end{array}$ \\
\hline $\begin{array}{l}\text { Utilização das } \\
\text { Informações para } \\
\text { Gestão }\end{array}$ & $\begin{array}{l}\text { "esse desempenho aqui estaria no nível de excelência. (...) para região, não reflete a realidade deles" } \\
\text { "você identifica essas diferenças e a ferramenta ajuda a chamar atenção" } \\
\text { "mostra as consequências e apoia as tomadas de decisões" }\end{array}$ & $\begin{array}{l}\text { Confiar nas } \\
\text { informações para } \\
\text { balizar decisões }\end{array}$ \\
\hline
\end{tabular}

Figura 3. Percepção dos gestores sobre o desenvolvimento da AO

Fonte: Dados da Pesquisa.

\section{CONSIDERAÇÕES FINAIS}

Esta pesquisa teve por objetivo investigar a presença dos elementos da $\mathrm{AD}$ na geração de AO, com base em um estudo de caso em uma organização que desenvolveu um sistema que já passou por todas as etapas de construção de um sistema de $\mathrm{AD}$ : desenho, implementação, uso e retroalimentação. Foram entrevistadas três pessoas diretamente envolvidas com planejamento e implantação do sistema. As entrevistas semiestruturadas foram orientadas pela literatura de base que aponta a presença dos elementos.

Analisando as falas dos entrevistados, verifica-se que o sistema de $\mathrm{AD}$, utilizado pela organização, foi projetado com base em um ciclo contínuo de reflexão, visto que as experiências de planejamento estratégico anteriores não prosperaram. Identifica-se pelos relatos que, com a operacionalização do sistema, a organização conseguiu se dar conta da realidade enfrentada, detectar e corrigir problemas que existiam e não eram conhecidos. Pode-se pensar em ações necessárias para desenvolver melhorias e solucionar esses problemas.

Como a literatura aponta, a aprendizagem surge nos indivíduos, e se torna organizacional quando é desenvolvida pela experiência e ações dos seus membros. No caso em estudo, percebe 
que o sistema de $\mathrm{AD}$ foi uma forma encontrada para socializar os conhecimentos pela comunicação e divulgação dos objetivos perseguidos, indicadores e metas que orientaram o sistema avaliativo.

Percebe-se que a comunicação permeia todo o processo de $\mathrm{AD}$, pois explicita o que se deseja com a construção de métricas e estabelecimento de metas. Estas, por sua vez, fomentam a utilização das informações para gestão e garantem feedback oportuno, permitindo a comparação dos resultados obtidos com aqueles esperados, definidos pelas metas colocadas.

Esse feedback proporciona a participação de todos os envolvidos, interessados nos resultados apresentados, fazendo com que a organização possa verificar o alcance dos objetivos estratégicos perseguidos e periodicamente retroalimentar o sistema. Quando entender que é conveniente revisar sua estratégia, a organização poderá rever suas crenças, comportamentos e ações, e estará mais preparada para as mudanças ambientais.

Os resultados limitam-se à apresentação de respostas dos entrevistados aos questionamentos levantados pelas pesquisadoras acerca do que mostra a literatura consultada sobre aprendizagem na $\mathrm{AD}$. Entendem as pesquisadoras que os entrevistados estavam cientes quanto à finalidade científica das perguntas e às implicações para si e para a organização das suas falas, o que pode ter limitado as respostas dadas. Sugere-se para futuras pesquisas investigação em outras organizações para comparar as experiências e ampliar número de entrevistados.

\section{REFERÊNCIAS}

Alvesson, M. (2003). Beyond neopositivists, romantics, and localists: A reflexive approach to interviews in organizational research. Academy of management review, 28(1), 13-33.

Amaratunga, D., \& Baldry, D. (2002). Moving from performance measurement to performance management. Facilities, 20(5/6), 217-223.

Amaratunga, D., Baldry, D., \& Sarshar, M. (2000). Assessment of facilities management performance - what next? Facilities, 18(1/2),66-75.

Argote, L. (2011). Organizational learning research: Past, present and future. Management Learning, 42(4), 439-446.

Argyris, C. (1977a). Double Looping Learning in organizations. Harvard Business Review, (Sept./Oct.), 115-125.

Argyris, C. (1977b). Organizational learning and management information systems. Accounting, Organizations and Society, 2(2), 113-123.

Batac, J., \& Carassus, D. (2009). Interactions between control and organizational learning in the case of a municipality: A comparative study with Kloot (1997). Management Accounting Research, 20(2), 102-116.

Bido, D. S., Godoy, A. S., Araujo, B. F. V. B. de, \& Louback, J. C. (2010). Articulação entre as aprendizagens individual, grupal e organizacional: um estudo no ambiente industrial. $R A M$. Revista de Administração Mackenzie, 11(2), 68-95.

Bititci, U. S., Garengo, P., Ates, A., \& Nudurupati, S. S. (2015). Value of maturity models in performance measurement. International Journal of Production Research, 53(10), 3062-3085.

Brudan, A. (2010). Rediscovering performance management: Systems, learning and integration. Measuring Business Excellence, 14(1), 109-123. 
Buckmaster, N. (1999). Associations between outcome measurement, accountability and learning for non-profit organizations. International Journal of Public Sector Management, 12(2), 186197.

Canonico, P., De Nito, E., Esposito, V., Martinez, M., Mercurio, L., \& Iacono, M. P. (2015). The boundaries of a performance management system between learning and control. Measuring Business Excellence, 19(3), 7-21.

Coad, A. (1996). Smart work and hard work: explicating a learning orientation in strategic management accounting. Management Accounting Research, 7(4), 387-408.

Cucchi, M. B., \& Barcellos, P. F. P. (2018). O Papel da Liderança no Processo de Mudança e Aprendizagem Organizacional: Estudo Multicaso nas Empresas Duradouras do Setor Metalmecânico de Marau, RS, Brasil. Pensamento \& Realidade, 33(4), 97-122.

Denzin, N. K., \& Lincoln, Y. S. (2006). O Planejamento da Pesquisa Qualitativa: Teorias e Abordagens (2a ed.). Porto Alegre: Artmed.

Kloot, L. (1997). Organizational learning and management control systems: responding to environmental change. Management Accounting Research, 8(1), 47-73.

Leitch, C., Harrison, R., Burgoyne, J. G., \& Blantern, C. (1996). Learning organizations: the measurement of company performance. Journal of European Industrial Training, 20(1), 31-44.

Lukka, K., \& Modell, S. (2010). Validation in interpretive management accounting research. Accounting, Organizations and Society, 35(2010), 462-477.

Moynihan, D. P. (2005). Goal-based learning and the future of performance management. Public Administration Review, 65(2), 203-216.

Oliver, J. (2009). Continuous improvement: Role of organizational learning mechanisms. International Journal of Quality and Reliability Management, 26(6), 546-563.

Oyadomari, J. C. T, Pedrique, A. L., Bido, D. S., \& Rezende, A. J. (2014). Uso do controle gerencial e decisões em organizações de saúde brasileiras: um estudo exploratorio. Brazilian Business Review, 11(2), 1-34.

Pekkola, S., Hildén, S., \& Rämö, J. (2015). A maturity model for evaluating an organization's reflective practices. Measuring Business Excellence, 19(4), 17-29.

Sampieri, R. H.; Collado, C. F. \& Lucio, M. D. P. B. (2013). Metodologia da Pesquisa 5. ed. Porto Alegre: Penso Editora, 2013. 624 p.

Senge, P. M., \& Sterman, J. D. (1992). Systems thinking and organizational learning: Acting locally and thinking globally in the organization of the future. European Journal of Operational Research, 59(1), 137-150.

Shurafa, R., \& Mohamed, R. B. (2016). Management control system, organizational learning, and firm's performance: An empirical study from developing economy. International Journal of Advanced and Applied Sciences, 3(10), 79-88. 
Simons, R. (1990). The role of management control systems in creating competitive advantage: New perspectives. Accounting, Organizations and Society, 15(1), 127-143.

Twining, P., Heller, R. S., Nussbaum, M., \& Tsai, C. C. (2016). Some guidance on conducting and reporting qualitative studies. Computers \& Education, 106, 1-9.

Valmorbida, S. M. I., \& Ensslin, L. (2016). Construção de Conhecimento sobre Avaliação de Desempenho para Gestão Organizacional: uma Investigação nas Pesquisas Científicas Internacionais. Revista Contemporânea de Contabilidade, 13(28), 123-148.

Vergara, S. C. (2009). Métodos de coleta de dados no campo. São Paulo: Atlas.

Wouters, M. (2009). A developmental approach to performance measures - Results from a longitudinal case study. European Management Journal, 27(1), 64-78.

Yeo, R. (2002). From individual to team learning: practical perspectives on the learning organisation. Team Performance Management: An International Journal, 8(7/8), 157-170.

Yeo, R. (2003a). Linking organisational learning to organisational performance and success: Singapore case studies. Leadership \& Organization Development Journal, 24(2), 70-83.

Yeo, R. (2003b). The tangibles and intangibles of organisational performance. Team Performance Management: An International Journal, 9, 199-204.

Yin, R. K. (2015). Estudo de Caso: Planejamento e Métodos (5a ed.) Porto Alegre: Bookman. 